\title{
Relation of hypoxia inducible factor $1 \alpha$ and $2 \alpha$ in operable non-small cell lung cancer to angiogenic/molecular profile of tumours and survival
}

\author{
A Giatromanolaki', MI Koukourakis', E Sivridis', H Turley², K Talks², F Pezzella², KC Gatter ${ }^{2}$ and AL Harris ${ }^{3}$ \\ ${ }^{1}$ Departments of Pathology and Radiotherapy / Oncology, Democritus University of Thrace, P.O.Box 128, Alexandroupolis 68100, Greece; ${ }^{2}$ Nuffield Department \\ of Clinical Laboratory Sciences, John Radcliffe Hospital, Oxford, OX3 7LJ, UK; ${ }^{3}$ Imperial Cancer Research Fund, Molecular Oncology Laboratories, Institute of \\ Molecular Medicine, John Radcliffe Hospital, Oxford OX3 9DS, UK
}

\begin{abstract}
Summary Hypoxia inducible factors HIF1 $\alpha$ and HIF2 $\alpha$ are important proteins involved in the regulation of the transcription of a variety of genes related to erythropoiesis, glycolysis and angiogenesis. Hypoxic stimulation results in rapid increase of the HIF $1 \alpha$ and $2 \alpha$ protein levels, as a consequence of a redox-sensitive stabilization. The HIF $\alpha$ s enter the nucleus, heterodimerize with the HIF $1 \beta$ protein, and bind to DNA at the hypoxia response elements (HREs) of target genes. In this study we evaluated the immunohistochemical expression of these proteins in 108 tissue samples from non-small-cell lung cancer (NSCLC) and in normal lung tissues. Both proteins showed a mixed cytoplasmic/nuclear pattern of expression in cancer cells, tumoural vessels and tumour-infiltrating macrophages, as well as in areas of metaplasia, while normal lung components showed negative or very weak cytoplasmic staining. Positive HIF1 $\alpha$ and HIF2 $\alpha$ expression was noted in $68 / 108$ (62\%) and in 54/108 (50\%) of cases respectively. Correlation analysis of HIF2 $\alpha$ expression with HIF1 $\alpha$ expression showed a significant association $(P<$ $0.0001, \mathrm{r}=0.44)$. A strong association of the expression of both proteins with the angiogenic factors VEGF $(P<0.004)$, PD-ECGF $(P<0.003)$ and bFGF $(P<0.04)$ was noted. HIF1 $\alpha$ correlated with the expression of bek-bFGF receptor expression $(P=0.01)$, while HIF2 $\alpha$ was associated with intense VEGF/KDR-activated vascularization $(P=0.002)$. HIF2 $\alpha$ protein was less frequently expressed in cases with a medium microvessel density (MVD); a high rate of expression was noted in cases with both low and high MVD $(P=0.006)$. Analysis of overall survival showed that HIF2 $\alpha$ expression was related to poor outcome $(P=0.008)$, even in the group of patients with low MVD $(P=0.009)$. HIF1 $\alpha$ expression was marginally associated with poor prognosis $(P=0.08)$. In multivariate analysis HIF2 $\alpha$ expression was an independent prognostic indicator $(P=0.006$, t-ratio 2.7). We conclude that HIF1 $\alpha$ and HIF2 $\alpha$ overexpression is a common event in NSCLC, which is related to the up-regulation of various angiogenic factors and with poor prognosis. Targeting the HIF pathway may prove of importance in the treatment of NSCLC. (C) 2001 Cancer Research Campaign http://www.bjcancer.com
\end{abstract}

Keywords: non-small-cell lung cancer; hypoxia inducible factors; angiogenesis; prognosis

Hypoxia has been recognized as a key factor involved in the regulation of a cascade of physiological responses such as erythropoiesis (Gopfert et al, 1996), glycolysis (Ebert et al, 1996), glucose transport (Tagaki et al, 1998), angiogenesis and vasodilatation (Griffiths et al, 1997; Carmeliet et al, 1998; Faller, 1999). A large group of genes that includes erythropoietin (Goldberg et al, 1988), nitric oxide synthase (Palmer et al, 1998), tyrosine hydroxylase (Norris and Millhorn, 1995), VEGF (Forsythe et al, 1996; Ema et al, 1997), lactate dehydrogenase, haem oxygenase, transferin receptor and others are regulated by hypoxia (Blancher and Harris, 1998). Cells, whether normal or malignant, have the ability to 'sense' low oxygen conditions, probably via a haem flavo-oxido-reductase protein or even through hypoxia-stimulated release of reactive oxygen species from mitochondria (Chandel et al, 2000), which activates a signalling pathway for the expression of the hypoxia-regulated genes.

HIF1 is a heterodimer of 2 basic-helix-loop-helix PAS domain proteins; HIF $1 \alpha$ (120 kDa protein) and HIF1 $\beta$ (91-94 kDa protein also called as aryl-hydrocarbon-nuclear receptor translocator,

Received 27 March 2001

Revised 4 June 2001

Accepted 12 June 2001

Correspondence to: AL Harris
ARNT1 and 2) (Semenza et al, 1991; Semenza and Wang 1992). Increased intracellular content of the hypoxia-inducible factor 1 (HIF1) occurs immediately following hypoxia sensing. HIF $1 \beta$ is present constitutively and usually does not change following hypoxic stimulation. In contrast, HIF $1 \alpha$ levels are maintained at low levels under normoxic conditions due to continuous degradation via the ubiquitin-dependent proteasome pathway (Huang et al, 1996). Hypoxic stimulation results in rapid increase of the HIF1 $\alpha$ protein levels, which is not a result of increased mRNA transcription or translation but rather a result of a redox-sensitive stabilization (Huang et al, 1998). Following HIF1 heterodimerization the complex enters into the nucleus and binds to DNA at the hypoxia response elements (HREs) of target genes.

More recently new molecules, HIF $2 \alpha$, (or endothelial PAS domain protein 1, EPAS1 or HIF1 $\alpha$-like factor, HLF) and HIF3 $\alpha$ have been identified with very similar characteristics to HIF $1 \alpha$ in dimerization with HIF1 $\beta$ and DNA binding (Ema et al, 1997; Gu et al, 1998). HIF2 regulates, similarly to HIF1, the transcription of hypoxia-regulated genes such as $V E G F$ and the endothelial cellspecific receptor tyrosine kinase gene Tie-2 (Tian et al, 1997). HIF $2 \alpha$ was believed to be specifically expressed in endothelial cells and is an important molecule during vasculogenesis (Tian et al, 1997). A recent study, however, showed that HIF $2 \alpha$ is also expressed in fibroblasts and in epithelial cells (Wiesner et al, 1998). 
In the present study we examined the expression patterns of HIF $1 \alpha$ and of HIF $2 \alpha$ in normal lung and in a series of non-smallcell lung carcinomas. The expression of HIFs was analysed in comparison with the microvessel density, with the expression of multiple angiogenic factors and receptors as well as with the expression of onco-proteins, previously shown to have a role in lung cancer. The prognostic role of HIF expression was also studied.

\section{MATERIALS AND METHODS}

We examined 108 tumour samples from patients with early operable (T1,2-N0,1-M0 staged) non-small-cell lung cancer (72 squamous and 36 adenocarcinomas). 12 samples from normal lung obtained during thoracic surgery for reasons other than lung cancer were also examined. Histological diagnosis, grading and Nstage was done on haematoxylin-eosin stained sections. 48 patients had T1-stage and $60 \mathrm{~T} 2$-stage disease. Node involvement (N1-stage) was present in $34 / 108$ patients. Histological grade 3 was noted in 59/108 and grade $1 / 2$ in $49 / 108$ patients. 84 patients were male and 24 female, their ages ranging from 35 to 74 years (median 63). Survival data (overall survival) were available in $98 / 108$ patients. Patients dying within 60 days after operation were excluded, so as to avoid bias from perioperative death. The followup of surviving patients at the time of analysis was 621-2500 days (median 1720 days).

\section{Assessment of HIF1 $\alpha$ and HIF2 $\alpha$ protein expression}

The HIF $1 \alpha$ and HIF $2 \alpha$ proteins were detected using the ESEE 122 (IgG1 Mab; dilution 1:20) and the EP190b (IgG1 Mab; neat) as we previously described (Wiesner et al, 1998; Talks et al, 2000). Sections were deparaffinized and peroxidase was quenched with methanol and $\mathrm{H}_{2} \mathrm{O}_{2} 3 \%$ for 15 minutes. Microwaving for antigen retrieval was used $(3 \times 4 \mathrm{~min})$. The primary antibodies were applied for 90 minutes. Following washing with TBS, sections were incubated with a secondary anti-rabbit anti-mouse antibody (Kwik Biotinylated Secondary, 0.69A Shandon-Upshaw) for 15 min and washed in TBS. Kwik Streptavidin peroxidase reagent (039A Shandon-Upshaw) was applied for $15 \mathrm{~min}$ and sections were again washed in TBS. The colour was developed by $15 \mathrm{~min}$ incubation with DAB solution and sections were weakly counterstained with haematoxylin. Breast cancer tissue sections with strong nuclear HIF $1 \alpha$ and HIF2 $\alpha$ expression were used as positive controls. Normal mouse immunoglobulin-G was substituted for primary antibody as the negative control (same concentration as the test antibody).

The percentage of cells expressing HIF $1 \alpha$ or HIF $2 \alpha$ in the cytoplasm and in the nuclei was separately assessed. The intensity of the cytoplasmic staining was also scored as absent, weak, moderate and strong.

\section{Assessment of microvessel density}

The JC70 monoclonal antibody (DAKO) recognizing the CD31 pan-endothelial antigen (platelet/endothelial cell adhesion molecule; PECAM-1) was used for microvessel and single endothelial cell staining on $5 \mu \mathrm{m}$ paraffin-embedded sections. We used the alkaline phosphatase/anti-alkaline phosphatase (APAAP) procedure as previously described (Giatromanolaki et al, 1998). Sections were dewaxed, rehydrated and pre-digested with protease type XXIV for $20 \mathrm{~min}$ at $37^{\circ} \mathrm{C}$. JC70 (1:50) was applied at room temperature for $30 \mathrm{~min}$ and washed in TBS. Rabbit anti-mouse antibody 1:50 (v/v) was applied for $30 \mathrm{~min}$, followed by application of mouse APAAP complex 1:1 (v/v) for $30 \mathrm{~min}$. After washing in TBS, the last 2 steps were repeated for $10 \mathrm{~min}$ each. The colour was developed by $20 \mathrm{~min}$ incubation with New Fuchsin solution.

Microvessel counting was used for angiogenesis assessment. For eye appraisal sections were scanned at low power $(\times 40$ and $\times 100)$ and afterwards at $\times 200$ field so as to group cases in 3 vascular grade categories (low, medium and high). The areas of the highest vascularization were chosen at low power $(\times 100)$ and microvessel counting followed on 3 chosen $\times 200$ fields of the highest density. The microvessel score (MS) was the sum of the vessel counts obtained in these 3 fields. Microvessels adjacent to normal lung were excluded from the appraisal. Vessels with a clearly defined lumen or well defined linear vessel shape but not single endothelial cells were taken into account for microvessel counting.

\section{Assessment of VEGF and of VEGF/KDR-activated microvessel density}

The VEGF expression was assessed with the VG1 Mab (IgG isotype) recognizing the 121,165 and 189 isoforms of $\operatorname{VEGF}(21)$. The VEGF/KDR complex was assessed with the $11 \beta 5 \mathrm{Mab}$, an IgM $\mu$ isotype produced using the VEGF $\mathrm{Hu} \mathrm{NH} 2$-terminus as an immunogen (Brekken et al, 1998). Sections were dewaxed, rehydrated and microwaving $(4 \min \times 2)$ for antigen retrieval was applied. $5 \mu \mathrm{m}$ paraffin-embedded sections were stained using the alkaline phosphatase/anti-alkaline phosphatase (APAAP) procedure. The primary Abs (1:4 dilution) were applied at room temperature for 1 hour and washed in TBS. Rabbit anti-mouse antibody 1:50 (v/v) was applied for $30 \mathrm{~min}$, followed by application of mouse APAAP complex 1:1 (v/v) for $30 \mathrm{~min}$. After washing in TBS, the last 2 steps were repeated for $10 \mathrm{~min}$ each. The colour was developed by 15 min incubation with Fast red solution and sections were weakly counterstained with haematoxylin. Nonspecific immunoglobulins were substituted for primary antibody as negative controls (same concentration as the test antibody).

The percentage of cancer cells with cytoplasmic VEGF reactivity was assessed by 2 independent observers at $\times 200$ magnification as previously reported (Giatromanolaki et al, 1998). The VEGF/KDR-positive microvessel density (activated MVD, aMVD) was assessed at the tumoural invading front as previously reported (Koukourakis et al, 2000).

\section{Assessment of thymidine phosphorylase expression}

Thymidine phosphorylase (TP; platelet-derived endothelial cell growth factor, PD-ECGF) expression was assessed with the PGF.44C monoclonal antibody using the streptavidin-biotin-peroxidase technique as previously described (Koukourakis et al, 1997a). The percentage of cancer cells with strong cytoplasmic/nuclear reactivity was recorded.

\section{Assessment of bFGF and bFGF-Bek-receptor expression}

The cytoplasmic basic Fibroblast Growth Factor (bFGF) and its 'bek' receptor (FGFR-2) expression was assessed in cancer cells, 
using the APAAP technique. We used the FGF-2 (147)-G and the Bek(C-17)-G MAbs respectively (Santa Cruz Biotechnology) as previously reported (Giatromanolaki et al, 2000). The percentage of cancer cells with positive cytoplasmic reactivity was recorded.

\section{Assessment of other immunohistochemical variables}

Proliferative index was assessed with the monoclonal antibody Ki67. Frozen material was taken from 2 separate areas of the tumour and the Ki67 assessment was based on the average value. Three groups were considered based on the percent of stained nuclei: $0-10 \%=$ low proliferative index, $10-40 \%=$ medium and $>40 \%=$ high (Tungekar et al, 1991).

The bcl-2 cytoplasmic protein expression and the p53 protein nuclear accumulation was assessed with the clone 100 (Dako) and the CM11(Dako) MoAbs respectively, as previously described (Giatromanolaki et al, 1998).

The EGFR, c-erbB-2 and episialin MUC-1 expression was also assessed (data not shown).

\section{Assessment of necrosis}

The percentage of optical fields $(\times 250)$ with necrosis was recorded by 3 observers separately. Necrotic areas in more than $50 \%$ of the examined fields (mean value of the score given by the observers) was scored as extensive and, in less than $50 \%$, as limited.

\section{Statistical analysis}

Statistical analysis and graphic presentation were performed using the GraphPad Prism 2.01 package (GraphPad, San Diego CA, www.graphpad.com). The Fisher's exact test, the chi-square $t$-test or the unpaired two-tailed $t$-test was used for testing relationships between categorical variables as appropriate. Linear regression analysis was used to assess correlation between continues variables. Survival curves were plotted using the method of Kaplan-Meier, and the log-rank test was used to determine statistical differences between life tables. A Cox proportional hazard model was used to assess the effects of patient and tumour variables on overall survival. A $P$ value $\leq 0.05$ was considered significant.

\section{RESULTS}

\section{Immunostaining of normal lung and cancer}

Both HIF $1 \alpha$ and HIF $2 \alpha$ showed a similar pattern of normal tissue staining. Samples from normal lung and areas distal to the tumour showed a weak or negative cytoplasmic reactivity of the bronceal epithelium, while alveolar epithelium and stroma were negative (Figure 1A). Normal bronchial and alveolar epithelium proximal to the tumour showed weak or even intense cytoplasmic staining. Alveolar macrophages and plasma cells in the normal lung were negative (Figure 1E), while tumour-infiltrating macrophages (CD68 positive cells identified with immunohistochemistry in parallel sections) showed intense cytoplasmic and nuclear reactivity (Figure 1F). Chondrocytes persistently showed a pure and strong nuclear reactivity (Figure 1A), which renders this finding an internal marker of positive staining. Normal vasculature was negative, while a strong cytoplasmic and/or nuclear staining of the endothelium was noted within the tumoural tissue and the invading front (Figure 1G). Areas of squamous metaplasia showed strong mixed cytoplasmic/nuclear reactivity (Figure 2A).

The expression of both HIF $1 \alpha$ and HIF $2 \alpha$ in cancer cells, both in adenocarcinomas and squamous tumours, was mixed cytoplasmic and nuclear (Figures 1C,D and 2B,C) and the percentage of stained cells was largely varying among cases. The intensity of staining varied among cases. Absent or weak staining was considered as negative, while moderate or strong as positive. Cytoplasmic staining of the stromal fibroblasts also varied among samples.

\section{Scoring of HIF expression in cancer cells}

HIF $1 \alpha$ and HIF $2 \alpha$ expression was both cytoplasmic and nuclear. Cytoplasmic staining was scored as absent, weak, moderate and strong. Nuclear expression, when present, was accompanied with moderate/strong cytoplasmic reactivity, although pure nuclear expression was occasionally noted. The extent of staining also varied among tumours. The percentage of cancer cells with HIF $1 \alpha$ moderate/strong cytoplasmic (and/or nuclear) reactivity ranged from $0 \%$ to $90 \%$ (median $80 \%$; mean $63 \%$ ). The percentage of HIF2 $\alpha$-positive cancer cells with moderate/strong cytoplasmic (and/or nuclear) expression ranged from $0 \%$ to $90 \%$ (median $45 \%$; mean $43 \%$ ).

Tumours were scored in a 3-scale system according to the intensity and extent of staining: score 1, tumours with absent or weak cytoplasmic reactivity and no nuclear reactivity; score 2 , tumours with moderate/strong cytoplasmic reactivity in a percentage of cancer cells lower than the mean value and no nuclear reactivity; score 3 , tumours with moderate/strong cytoplasmic reactivity in a percentage of cancer cells higher than the mean value; score 4, tumours with a clear nuclear reactivity (with or without cytoplasmic reactivity regardless of the intensity). Tumours with score 1 and 2 were grouped as bearing low HIF reactivity, while tumours with score 2 and 3 as bearing high HIF reactivity. Using these criteria, 40 cases had low and 68 high HIF $\alpha$ reactivity. 54 cases had low and 44 had high HIF $\alpha$ reactivity.

\section{Correlation between HIF1 $\alpha$ and HIF2 $\alpha$}

Correlation analysis of HIF $2 \alpha$ expression with HIF $1 \alpha$ expression showed a significant association $(P<0.0001, \mathrm{r}=0.44)$. Out of 68 cases with high HIF1 $\alpha$ expression $43(63 \%)$ also had high HIF2 $\alpha$ expression, while $11 / 29$ (37\%) cases with low HIF1 $\alpha$ expression had high HIF2 $\alpha$ expression $(P=0.0006$; Fisher's exact $t$-test).

\section{HIF $1 \alpha / 2 \alpha$ and histopathological variables}

HIF2 $\alpha$ expression was significantly more frequent in squamous cell carcinomas than in adenocarcinomas (30/72 vs. $24 / 36 ; P=$ 0.02), while HIF $\alpha$ was not related to histology. Although HIF1 $\alpha$ expression was more frequent in $\mathrm{T} 2$ than in $\mathrm{T} 1$ stage the difference was not significant $(42 / 60(70 \%)$ vs. $26 / 48(54 \%) ; P=0.11)$. High Ki67 proliferation index was not related to either HIF1 $\alpha$ and HIF $2 \alpha$ expression $(P>0.81)$. There was no association of HIF1 $\alpha$ and HIF $2 \alpha$ expression with $\mathrm{N}$-stage, histological grade, or the extent of necrosis (data not shown)

\section{HIF $1 \alpha / 2 \alpha$ and angiogenic profile of tumours}

Using the 33rd and 66th percentile as cut-off point we grouped our cases in 3 categories of low, medium and high angiogenic 


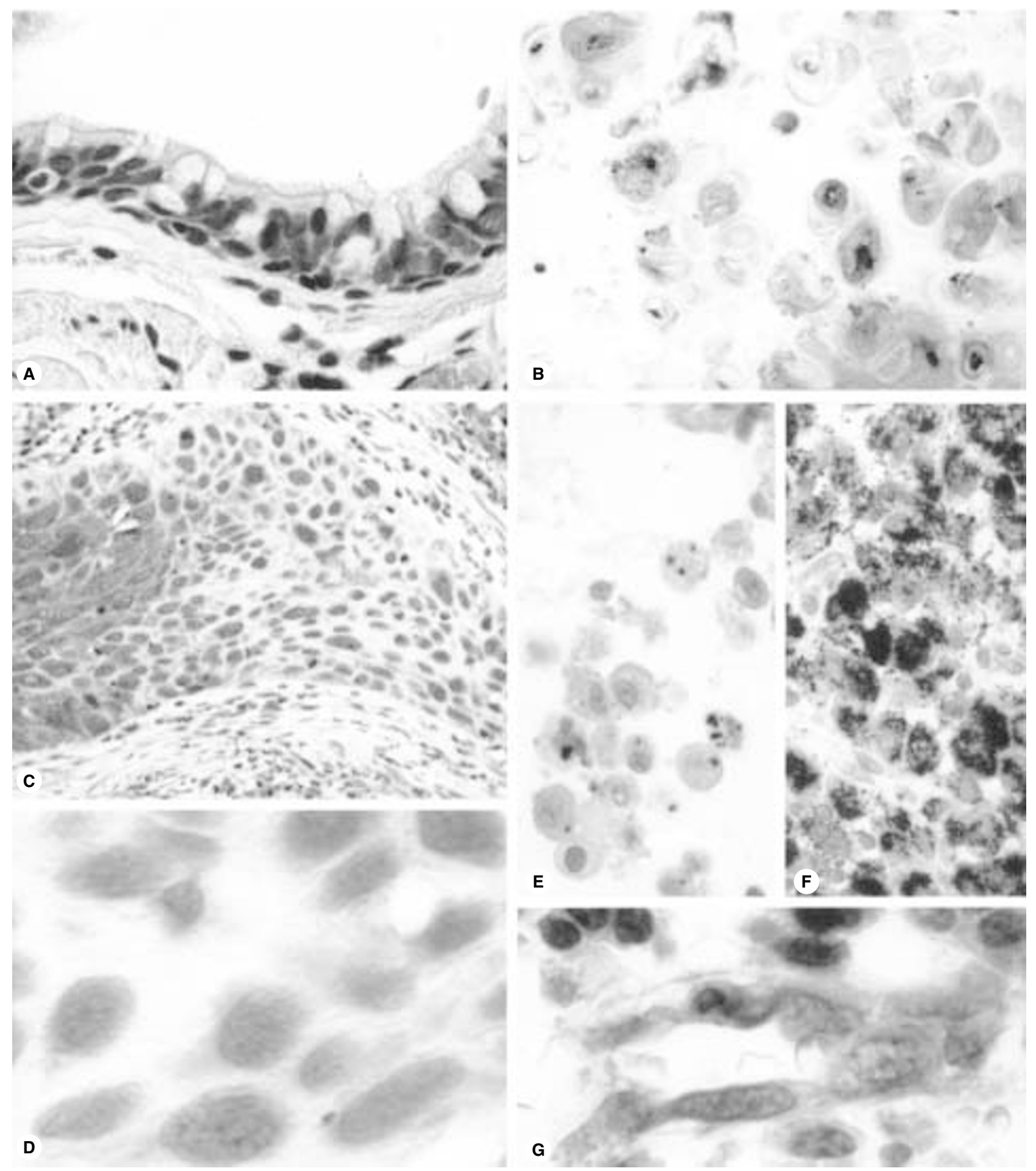

Figure 1 Expression of HIF1 $\alpha$ in normal and neoplastic lung. (A) Normal bronchial epithelium does not express HIF1 $\alpha(\times 200)$; (B) Nuclear staining of chondrocytes ( $\times$ 400); (C) Nuclear and mixed cytoplasmic/nuclear HIF1 $\alpha$ staining of squamous cell lung cancer $(\times 200)$; (D) Absence of HIF1 $\alpha$ staining in alveolar macrophages $(\times 400)$; (E) Intense HIF1 $\alpha$ staining of tumour-infiltrating macrophages $(\times 400)$; (F) Nuclear HIF1 $\alpha$ staining of squamous cancer cells $(\times 400)$; (G) Nuclear/cytoplasmic HIF1 $\alpha$ staining of the endothelium $(\times 400)$

factor and receptor expression. For VEGF, low, medium and high expression refers to $0-30 \%, 31-69 \%$ and $70-100 \%$ of cells with positive reactivity. For TP, low, medium and high expression refer to $0-10 \%, 11-49 \%$ and $50-100 \%$ of cells with strong TP reactivity. For bFGF, low, medium and high expression refer to $0-59 \%$, $60-79 \%$ and $80-100 \%$ of cells stained. For bFGF-bek-receptor the percentage of stained cells used to define low, medium and high reactivity were $0-9 \%, 10-20 \%$ and $>20 \%$ respectively. Cases with $<4,4-10$ and $>10 \mathrm{VEGF/KDR-positive} \mathrm{vessels} \mathrm{in} \mathrm{the}$ tumour-invading front (points that correspond to the 33rd and 66th percentile) were grouped as bearing low, medium and high activated MVD respectively. Similarly, the $33 \mathrm{rd}$ and 66 th percentile of 


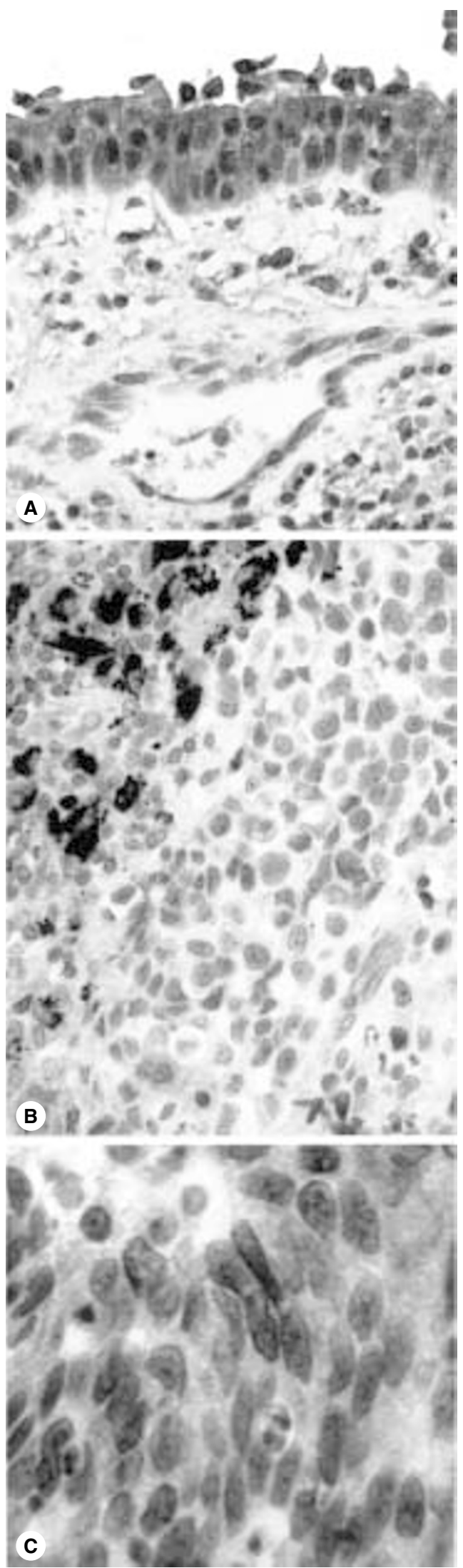

Figure 2 Expression of HIF2 $\alpha$ in metaplasia and neoplastic lung (A) Intense nuclear and cytoplasmic HIF2 $\alpha$ expression in lung metaplasia ( $\times 200$ ); (B) Nuclear expression of HIF2 $\alpha$ in squamous cell lung cancer and tumour-infiltrating macrophages ( $\times 200$ ); (C) Nuclear HIF2 $\alpha$ expression in squamous cell lung cancer $(\times 400)$
MVD was used to define low ( $<32$ vessels), medium (33-70 vessels) and high ( $>70$ vessels) MVD groups.

Table 1 shows the association of HIF $1 \alpha$ and HIF $2 \alpha$ expression with microvessel density and the expression of angiogenic factors and angiogenic factor receptors. A significant association of both HIF $1 \alpha$ and HIF $2 \alpha$ with all 3 angiogenic factors (VEGF, PD-ECGF and bFGF) examined was noted. $88 \%$ and $70 \%$ of cases with high VEGF expression had high HIF $1 \alpha$ and HIF $2 \alpha$ expression, respectively, vs. $48 \%(\mathrm{HIF} 1 \alpha)$ and $38 \%(\mathrm{HIF} 2 \alpha)$ of cases with low/medium VEGF expression $(P=0.0002$; Fisher's exact $t$ test). Similar differences were noted for PD-ECGF (thymidine phosphorylase) and bFGF ( $P=0.0004$ to 0.006$)$. High bFGF-bekreceptor (bFGFR) expression was associated with high HIF1 $\alpha$ expression $(P=0.007)$ but not with HIF2 $\alpha$. On the contrary, HIF $2 \alpha$ expression was strongly associated with the VEGF/KDRactivated microvessel density in the invading tumour front $(P=$ 0.0009), while HIF $1 \alpha$ was not. Combining HIF $1 \alpha$ and HIF2 $\alpha$ expression (low/low vs. all others), a very strong association of HIF overexpression with VEGF $(P<0.0001)$ and with TP $(P=0.0004)$ was noted (data not shown).

Cases with high MVD were more frequently of high HIF $1 \alpha$ and HIF $2 \alpha$ expression as compared to the group of low/medium MVD, but the difference did not reach significance $(P=0.18$ and 0.08 for HIF $1 \alpha$ and HIF $2 \alpha$, respectively). Of interest, the group of patients with medium MVD was strongly associated with low HIF2 $\alpha$ expression, while HIF2 $\alpha$ expression was similarly high in cases with low and high MVD ( $P=0.01$ and 0.008 , respectively).

A continuous variable analysis revealed that the mean percentage of HIF $1 \alpha$-positive cells (cells with moderate/strong cytoplasmic reactivity or nuclear expression) in cases with low/medium MVD was significantly lower than in cases with high MVD $(71 \pm 15$ vs. $60 \pm 26 ; P=0.03$; Figure 3a). Similarly, cases with low/medium

Table 1 Correlation of HIF $1 \alpha$ and HIF2 $\alpha$ expression with angiogenic factor expression and microvessel density in non-small-cell lung cancer

\begin{tabular}{|c|c|c|c|c|c|c|}
\hline \multirow{2}{*}{ Parameter } & \multicolumn{3}{|c|}{ HIF $1 \alpha$} & \multicolumn{3}{|c|}{ HIF2 $\alpha$} \\
\hline & Low & High & $P$ value & Low & High & $P$ value \\
\hline \multicolumn{7}{|l|}{ VEGF } \\
\hline low & 19 & 14 & & 22 & 11 & \\
\hline medium & 16 & 19 & 0.0002 & 20 & 15 & 0.004 \\
\hline high & 5 & 35 & & 12 & 28 & \\
\hline \multicolumn{7}{|l|}{ PD-ECGF } \\
\hline low & 17 & 22 & & 23 & 16 & \\
\hline medium & 17 & 16 & 0.006 & 22 & 12 & 0.003 \\
\hline high & 6 & 30 & & 10 & 26 & \\
\hline \multicolumn{7}{|l|}{ bFGF } \\
\hline low & 26 & 18 & & 28 & 16 & \\
\hline medium & 7 & 24 & 0.0004 & 14 & 17 & 0.04 \\
\hline high & 7 & 26 & & 1 & 2 & \\
\hline \multicolumn{7}{|l|}{ VEGF/KDR } \\
\hline low & 18 & 22 & & 27 & 13 & \\
\hline medium & 12 & 23 & 0.39 & 18 & 17 & 0.002 \\
\hline high & 10 & 23 & & 9 & 24 & \\
\hline \multicolumn{7}{|l|}{ bFGFR } \\
\hline low & 21 & 22 & & 25 & 18 & \\
\hline medium & 13 & 18 & 0.01 & 16 & 15 & 0.21 \\
\hline high & 6 & 28 & & 13 & 21 & \\
\hline \multicolumn{7}{|l|}{ MVD } \\
\hline low & 14 & 21 & & 14 & 21 & \\
\hline medium & 18 & 24 & 0.29 & 29 & 13 & 0.006 \\
\hline high & 8 & 23 & & 11 & 20 & \\
\hline
\end{tabular}



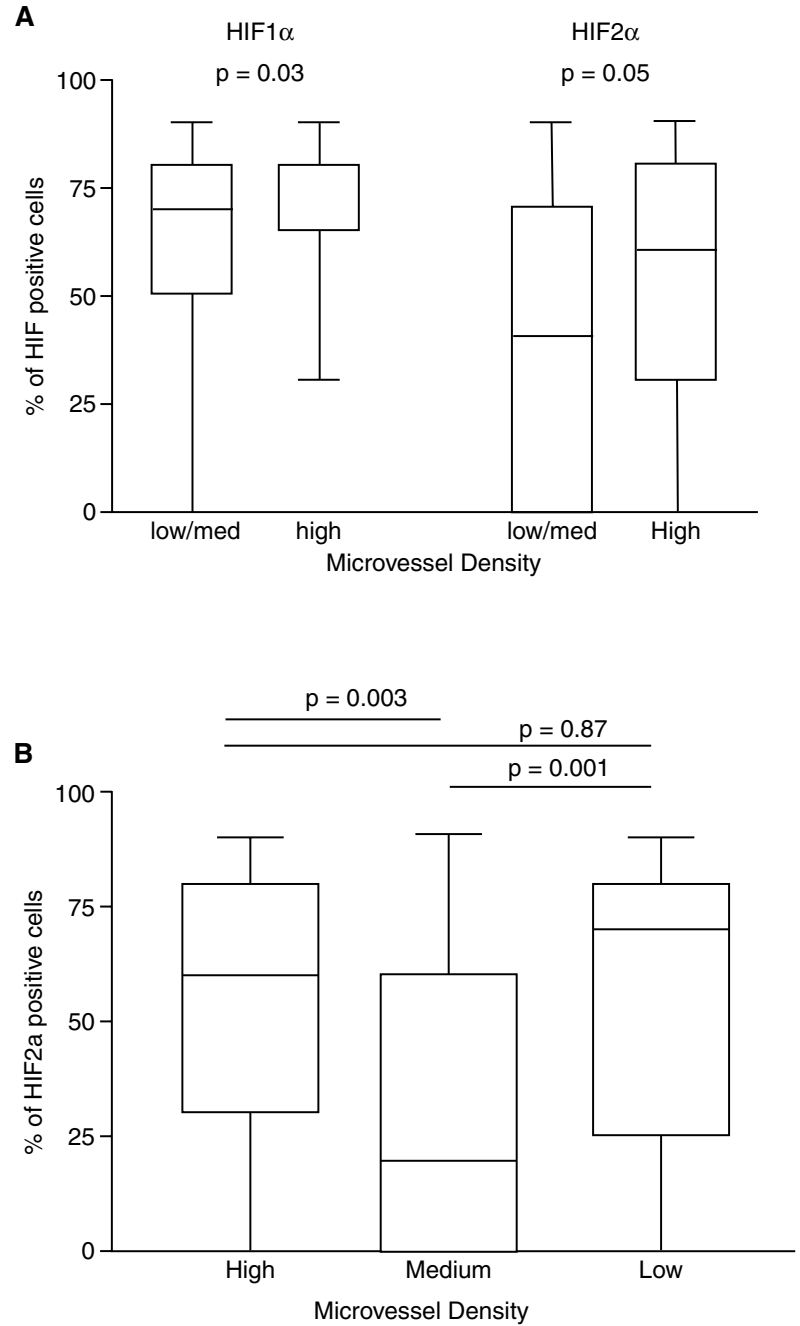

Figure 3 Percentage of cells with HIF1 $\alpha$ and $2 \alpha$ expression in 2 different microvessel density groups (low/medium vs. high; A). Percentage of cells with HIF2 $\alpha$ expression in 3 different microvessel density groups (low vs. medium vs. high; $\mathbf{B}$ ). Line in the boxes show the median value, the box edges the standard deviation and the bars the range

MVD had a lower percentage of HIF $2 \alpha$-positive cells compared to cases with high MVD (52 \pm 26 vs. $39 \pm 32 ; P=0.05$; Figure 3a) Further analysis, however, revealed a U-like shaped association of HIF $2 \alpha$ expression with MVD is shown in Figure 3b. Cases with high and low MVD had a significantly higher percentage of cells expressing HIF $2 \alpha$ as compared to cases with medium MVD.

\section{HIF $1 \alpha / 2 \alpha$ and other molecular parameters}

A significant inverse association of bcl-2 expression with both HIF $1 \alpha$ and HIF $2 \alpha$ was noted ( $P=0.02$ and 0.005 , respectively). p53 nuclear accumulation was significantly more frequent in the HIF $1 \alpha$ expressing cases $(P=0.04)$, (Table 2 ).

No association of HIF $1 \alpha$ and HIF $2 \alpha$ with EGFR, c-erb B-2 or episialine (MUC1) expression was noted (data not shown). A significant association of HIF $2 \alpha$ expression with c-erbB-2 expression was noted in poorly vascularized cases $(P=0.04$; data not shown).

\section{HIF $1 \alpha / 2 \alpha$ and survival}

Univariate analysis showed that HIF $2 \alpha$ expression was significantly associated with poor prognosis $(P=0.008)$, while HIF $1 \alpha$
Table 2 Correlation of HIF1 $\alpha$ and HIF2 $\alpha$ expression with cytoplasmic bcl-2 protein expression and p53 protein nuclear accumulation

\begin{tabular}{cccccccc}
\hline \multirow{2}{*}{ Parameter } & \multicolumn{3}{c}{ HIF1 $\alpha$} & & \multicolumn{3}{c}{ HIF2 $\alpha$} \\
\cline { 2 - 3 } & Low & High & $\boldsymbol{P}$ value & & Low & High & $\boldsymbol{P}$ value \\
\hline bcl-2 & & & & & & \\
neg & 28 & 60 & 0.02 & & 38 & 50 & 0.005 \\
pos & 12 & 8 & & & 16 & 4 & \\
p53 & & & & & & \\
neg & 25 & 28 & 0.04 & & 27 & 26 & 0.84 \\
pos & 15 & 40 & & 27 & 28 & \\
\hline
\end{tabular}

\section{A}
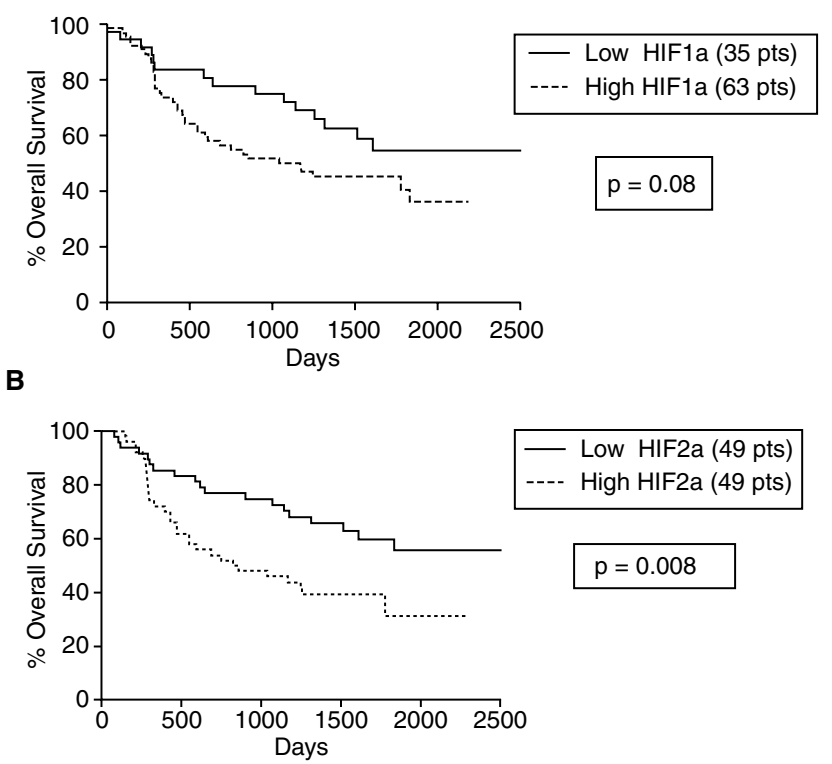

Figure 4 Kaplan-Meier survival curves of 98 patients with non-small-cell lung cancer stratified for $\mathrm{HIF} 1 \alpha(\mathbf{A})$ and $\mathrm{HIF} 2 \alpha(\mathbf{B})$ expression (high vs. low)

showed a marginal association $(P=0.08)$. Figures 4 A,B show the Kaplan-Meier survival curves plotted for HIF1 $\alpha$ and HIF2 $\alpha$ expression. The 5 year survival of patients with high HIF $2 \alpha$ expression was $32 \%$ vs. $58 \%$ of patients with low HIF2a expression. T,N-stage and MVD were also significantly associated with survival $(P=0.006,0.007$ and 0.005 , respectively).

We further analysed the survival of patients with low/medium MVD according to the HIF $1 \alpha$ and $2 \alpha$ expression (Figure 5A,B). A significantly worse prognosis of patients with low/medium MVD but high HIF2 $\alpha$ expression was noted $(P=0.04)$. This association was even stronger in patients with low MVD expressing HIF2 $\alpha$ $(P=0.009$; Figure 5c).

Table 3 shows the results obtained from multivariate analysis of death events in different models including HIFs and the parameters with important prognostic significance in univariate T-stage, $\mathrm{N}$-stage and microvessel density (MVD). Due to the close association of HIF $1 \alpha$ and HIF $2 \alpha$ with each other and with MVD, as well as due to the close association of $\mathrm{N}$-stage with MVD, only T-stage had an independent prognostic significance in the multivariate model that comprised all the examined parameters. In a multivariate model including T-stage, N-stage, MVD and HIF2 $\alpha$ expression we observed that HIF2 $\alpha$ had an independent prognostic meaning $(P=0.005$, t-ratio $=2.0)$. T-stage was also an independent 


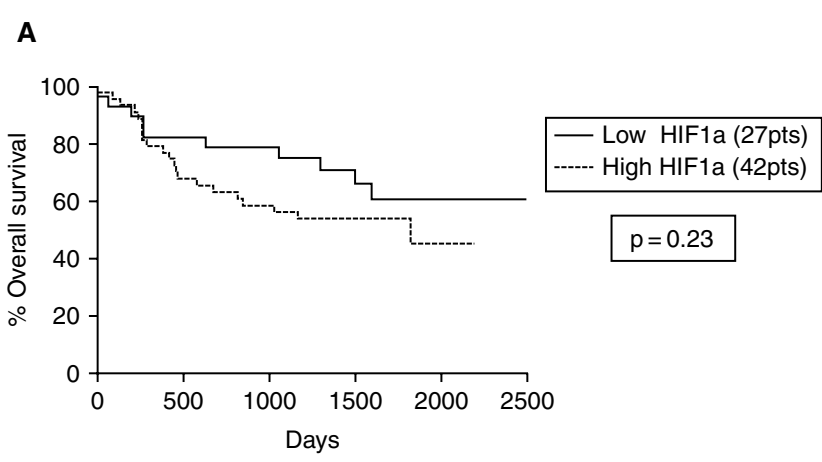

B
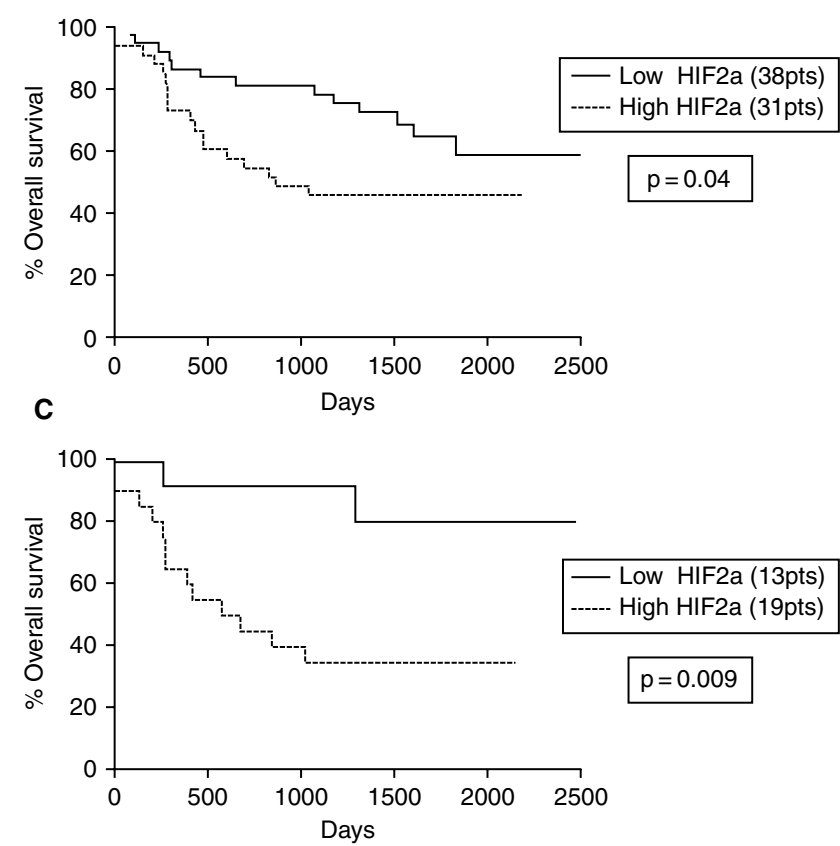

Figure 5 Kaplan-Meier survival curves in the low/medium microvessel density (MVD) group of patients (69 patients) stratified for HIF1 $\alpha$ (A) and HIF2 $\alpha$ (B) expression (positive vs. negative). In (C) stratification for HIF2 $\alpha$ has been performed in the low MVD group of patients (32 patients)

Table 3 Multivariate analysis of death events

\begin{tabular}{llcccc}
\hline \multirow{2}{*}{ Parameter } & \multicolumn{5}{c}{$P$ value/t-ratio } \\
\cline { 2 - 6 } & Model 1 & Model 2 & Model 3 & Model 4 & Model 5 \\
\hline HIF1a & $0.57 / 0.55$ & $0.20 / 1.26$ & - & $0.14 / 1.46$ & - \\
HIF2a & $0.11 / 1.60$ & - & $0.04 / 2.01$ & - & $0.03 / 2.20$ \\
T-stage & $0.009 / 2.65$ & $0.01 / 2.43$ & $0.006 / 2.78$ & $0.01 / 2.48$ & $0.005 / 2.86$ \\
N-stage & $0.12 / 1.56$ & $0.08 / 1.75$ & $0.13 / 1.51$ & $0.007 / 2.75$ & $0.01 / 2.39$ \\
MVD & $0.13 / 1.49$ & $0.10 / 1.64$ & $0.12 / 1.55$ & - & - \\
& & & & & \\
\hline
\end{tabular}

prognostic variable $(P=0.006$, t-ratio $=2.7)$. N-stage and MVD did not reach significance $(P=0.13$ and 0.12$)$ probably because of the strong association of the 2 variables with each other. HIF $1 \alpha$ was not revealed as an independent prognostic factor.

\section{DISCUSSION}

Once transformation has occurred, unrestrained cancer cell growth without a parallel formation of vessels leads to the establishment of intratumoral hypoxic conditions. Cells found 100-200 $\mu \mathrm{m}$ away from blood vessels are already hypoxic (Gatenby et al, 1988), which suggests that hypoxic conditions will have been established in a cluster of cells of about $0.5 \mathrm{~mm}$ diameter. Activation of the HIF1 pathway may therefore be expected to occur at a very early step of tumour progression. Indeed, HIF1 expression was found to be expressed in in situ carcinomas and also in premalignant conditions (Zhong et al, 1999). In our study we found areas of bronchial metaplasia which exhibited strong staining of both nuclei and cytoplasm. This may be due to early hypoxia, but other mechanisms such as the effects of cytokines e.g. TNF $\alpha$ or growth factors may be responsible. Since HIF1 and HIF2 stabilization up-regulates the expression of angiogenic and glycolytic pathways to restore oxygen homeostasis, HIFs may have an important role for the survival and growth of cancer. Indeed, recent experimental studies confirm that HIFs modulate gene expression resulting in increased angiogenesis and tumoural growth (Jiang et al, 1997; Maxwell et al, 1997).

The significance of HIFs expression in human tumours remains largely unexplored as monoclonal antibodies available for immunohistochemistry have been only recently developed. Zhong et al recently reported on the expression of HIF $1 \alpha$ in a panel of normal human tissues and benign or malignant tumours and first showed the expression of the molecule in a good percentage of human carcinomas (Zhong et al, 1999). However, studies on the association of HIF $1 \alpha$ and $2 \alpha$ expression with angiogenic factors and receptors, with microvessel density or with other molecular markers or with prognosis of human carcinomas are few.

In a study in brain tumours, Zagzag et al observed that HIF $1 \alpha$ and HIF $1 \beta$ expression is expressed around the areas of necrosis and in the invading front of brain tumours (Zagzag et al, 2000). These patterns show that, at least in part, HIF $1 \alpha$ expression is a result of differences in tissue oxygenation. In contrast, haemangioblastomas presented a homogeneous expression of HIF $1 \alpha$, suggesting an oncogenic reason for its up-regulation in this tumour type.

Using 2 novel antibodies for HIF $1 \alpha$ and HIF2 $\alpha$ (Talks et al, 2000 ), we focused on lung cancer. Expression of HIF $1 \alpha$ and $2 \alpha$ by cancer cells was mixed nuclear/cytoplasmic, which is in accordance with the staining patterns reported by Zhong et al (1999). Although it would be assumed that nuclear HIF is the active form, clearly it is synthesized in the cytoplasm and also degraded in the cytoplasm. There may be redistribution while collecting tissues, which would be difficult to control but the overall expression indicates up-regulation of the pathway selectively in cancer. Analysis based on pure nuclear expression showed very marginal or no statistical association with other molecular factors or prognosis, showing that strong cytoplasmic HIF expression, which is a tumour-specific finding, better reflects the HIF up-regulated pathway in paraffin-embedded material. This suggestion is in general accordance with the scoring system proposed by Zhong et al (1999). HIF $1 \alpha$ was more frequently overexpressed in lung cancer than HIF2 $\alpha$. Although both molecules were more frequently noted in larger tumours, we found no association of HIF-positive tumours with high Ki67 proliferation index. A strong association of high HIF $1 \alpha$ and HIF $2 \alpha$ expression with the expression of vascular endothelial growth factor (VEGF), thymidine phosphorylase (TP) and basic fibroblast growth factor (bFGF) was confirmed. Bek bFGF-receptor expression was significantly overexpressed in HIF1 $\alpha$-overexpressing cases, while activated VEGF/KDR angiogenesis was strongly related to HIF $2 \alpha$ expression by cancer cells. 
There was a strong association of HIF expression with multiple angiogenic factors and receptors so a higher MVD was expected in HIF-overexpressing cases. This was the case for HIF $2 \alpha$ which was associated with up-regulation of VEGF and its receptor but not for HIF $1 \alpha$ where the association was weaker for VEGF and not found for its receptor. For HIF $1 \alpha$ there was an association with up-regulation of bFGF and its receptor in contrast to HIF $2 \alpha$. These results will need to be confirmed but do suggest that each HIF may regulate some pathways more than others and may explain the existence of 2 such similar factors.

Although the chi-squared test shows a significant association of HIF2 $\alpha$ with MVD $(P=0.006)$, closer inspection showed a more complicated relationship. HIF2 $\alpha$ was higher in cases with high or low MVD but was significantly lower in cases with a medium degree of vascularization. This U-like-shaped association of HIF2 $\alpha$ with MVD is in accordance with previous studies of ours where not all VEGF-, TP- or bFGF-expressing tumours show an increase in angiogenesis (Koukourakis et al, 1997b, 2000; Giatromanolaki et al, 1998, 2000). We suggest that although hypoxia triggers the expression of a cascade of angiogenic factors through HIF stabilization, the process of angiogenesis is subject to other modulators. Strong expression of endogenous inhibitors of angiogenesis produced by cancer or stromal cells may therefore counter the effectiveness of the angiogenic cascade released by HIFs (Dong et al, 1997; Koukourakis et al, 1998), while a moderate vascularization may be enough for the restoration of oxygenation that may bring the HIF levels close to the normal level. HIF levels are normalized within minutes after the restoration of oxygenation (Wiesner et al, 1998). The presistent HIF expression in a group of highly angiogenic tumours may show an aggressive phenotype with high oxygen consumption as a result of the transformation itself and not of the hypoxic environment. For example, VHL mutations (Maxwell et al, 1999), activation of HIFs by MAP kinases (Mazure et al, 1999) or the IGF1 pathway (Feldser et al, 1999; Zundel et al, 2000) may be involved in the persistent HIF induction despite the restoration of oxygenated conditions.

Survival analysis showed that HIF2 $\alpha$ expression was significantly associated with worse prognosis, which was independent of the MVD. Indeed, stratification of poorly vascularized tumours according to HIF $2 \alpha$ expression showed a poorer prognosis of patients with HIF $2 \alpha$ overexpression. Patients bearing tumours with low MVD and high HIF $1 \alpha$ expression also did worse, but the difference was not significant. These findings show that HIFs may have an important role in tumour progression distinct from angiogenesis. The activation of the glycolytic pathway and increased glucose transport may give a survival and growth advantage to cancer cells growing in hypoxic conditions. A significantly poorer prognosis of patients with early stage HIF $1 \alpha$ positive cervical cancer has been also reported by Birner et al (2000), while a putative role of HIF $1 \alpha$ in defining poor response to radiotherapy and poor outcome has been reported in a more recent study (Aebersold et al, 2001). In contrast to these studies, Volm et al (2001) found a significant association of HIF $1 \alpha$ with a better survival in non-small-cell lung cancer. Although difficult to explain this later observation, an eventual U-like association of HIFs with angiogenesis (intense expression in tumours with very low and with very high angiogenesis) noted in our study shows that the prognostic role of HIFs in human malignancies may be more complicated.

Although, Zhong et al found a significant association of HIF $1 \alpha$ expression with Ki67 proliferation index (Zhong et al, 1999), we could not confirm this finding in the present study. Studies on apoptotic index may be useful in identifying a survival advantage conferred by HIFs. We also assessed whether HIF expression was associated with activated migration pathways such as c-erbB-2, EGFR and MUC1/episialin expression. Although such an association was not confirmed overall, analysis in the group of patients with poor vascularization showed a significant association of HIF $2 \alpha$ expression with c-erbB-2 overexpression $(P=0.04$, data not shown). C-erbB-2 is involved in epithelial cell migration and hypoxia has been shown to induce keratinocyte motility (de-Porter et al, 1994; O'Toole et al, 1997). Whether HIF expression activates migration-related pathways is unknown, but the observed association of HIF $2 \alpha$ expression with c-erbB-2 supports our previous findings that c-erbB-2 defines a group of poorly vascularized tumours associated with poor prognosis (Giatromanolaki et al, 1996). A similar association (although of borderline significance, between c-erbB-2 and HIF1a expression has been recently reported in breast cancer (Boss et al, 2001).

Comparative analysis of bcl-2 and HIF expression showed a significant inverse association of both HIF $1 \alpha$ and of HIF $2 \alpha$ with bcl-2 expression. A similar association has been reported by Zhong et al (1999). In previous studies we showed that bcl-2 expression cancer is associated with poor vascularization in lung and endometrial cancer (Koukourakis et al, 1997; Giatromanolaki et al, 1999) and also in breast cancer (unpublished data). We also reported an inverse association of bcl-2 expression with both VEGF and TP expression (Koukourakis et al, 2000). Indeed, in this study only $3 / 18$ bcl-2-positive tumours had high MVD. All these 3 cases had high HIF expression ( $P=0.06$; data not shown). The inverse association of $\mathrm{bcl} 2$ with HIF stabilization may be because such tumours are characterized by a less aggressive growth, which explains the excellent survival reported in patients with bcl-2-overexpressing lung carcinomas (Koukourakis et al, 1997, 2000). There may therefore be much less oxygen consumption and less metabolically driven hypoxia and, therefore, less induction of HIF. The marginal direct association of HIF $1 \alpha$ with p53 nuclear accumulation observed in this study and in the study by Zhong et al (1999) may be due to co-induction of both by hypoxia or stabilizing interactions of both proteins.

We conclude that HIF $1 \alpha$ and $2 \alpha$ expression is a common event in lung cancer, which occurs early in the development of the disease as shown by the strong expression in areas of metaplasia. The HIF pathway may therefore be a useful marker in assessing risk of malignancy and will be of interest to assess how this relates to progression and invasion. The HIF transcription pathway may also be a target for cancer prevention. Strong expression of both HIF $1 \alpha$ and $2 \alpha$ was related to up-regulation of multiple angiogenic factors and overexpression of angiogenic receptors by cancer cells and the endothelium. HIF $2 \alpha$ overexpression showed a strong association with poor survival, even in poorly vascularized cases. Therefore, HIFs confer aggressive tumour behaviour through both angiogenic-dependent and -independent pathways. Targeting the HIF pathway may prove of importance in the treatment of nonsmall-cell lung cancer.

\section{REFERENCES}

Aebersold DM, Burri P, Beer KT, Laissue J, Djonov V, Greiner RH and Semenza GL (2001) Expression of hypoxia-inducible factor-1 $\alpha$ : a novel predictive and prognostic parameter in the radiotherapy of orop haryngeal cancer. Cancer Res 61: $2911-2916$ 
Birner P, Schindl M, Obermair A, Plank C, Breitenecker G and Oberhuber G (2000) Overexpression of hypoxia-inducible factor $1 \alpha$ is a marker for an unfavorable prognosis in early-stage invasive cervical cancer. Cancer Res 60: 4693-4696

Blancher C and Harris AL (1998) The molecular basis of the hypoxia response pathway: tumour hypoxia as a therapy target. Cancer Metast Rev 17: 187-194

Bos R, Zhong H, Hanrahan CF, Mommers EC, Semenza GL, Pinedo HM, Abeloff MD, Simons JW, van Diest PJ and van der Wall E (2001) Levels of hypoxiainducible factor-1 $\alpha$ during breast carcinogenesis. J Natl Cancer Inst 93: 309-314

Brekken RA, Huang X, King SW and Thorpe PE (1998) Vascular endothelial growth factor as a marker of tumor endothelium. Cancer Res 58: 1952-1959

Carmeliet P, Dor Y, Herbert JM, Fukumura D, Brusselmans K, Dewerchin M, Neeman M, Bono F, Abramovitch R, Maxwell P, Koch CJ, Ratcliffe P, Moons L, Jain RK, Collen D, Keshert E and Keshet E (1998) Role of HIF-1 $\alpha$ in hypoxia-mediated apoptosis, cell proliferation and tumour angiogenesis. Nature 394: $485-490$

Chandel NS, McClintock DS, Feliciano CE, Wood TM, Melendez JA, Rodriguez AM and Schumacker PT (2000) Reactive oxygen species generated at mitochondrial complex II stabilize HIF- $1 \alpha$ during hypoxia: a mechanism of $\mathrm{O}_{2}$ sensing. J Biol Chem May 31

de-Porter CR, Eeckhout I, Schelfhout AM, Geerts ML and Roels HJ (1994) Keratinocyte induced chemotaxis in the pathogenesis of Paget's disease of the breast. Histopathology 24: 349-356

Dong Z, Kumar R, Yang X and Fidler IJ (1997) Macrophage-derived metalloelastase is responsible for the generation of angiostatin in Lewis lung carcinoma. Cell 88: $801-810$

Ebert BL, Gleadle JM, O'Rourke JF, Bartlett SM, Poulton J and Ratcliffe PJ (1996) Isoenzyme specific regulation of genes involved in energy metabolism by hypoxia: similarities with the regulation of erythropoietin. $J$ Biochem $\mathbf{3 1 3}$ : 809-814

Ema M, Taya S, Yokotani N, Sogawa K, Matsuda Y and Fujii-Kuriyama Y (1997) A novel bHLH-PAS factor with close sequence similarity to hypoxia-inducible factor $1 \alpha$ regulates the VEGF expression and is potentially involved in lung and vascular development. Proc Natl Acad Sci USA 94: $4273-4278$

Faller DV (1999) Endothelial cell responses to hypoxic stress. Clin Exp Pharmacol Physiol 26: 74-84

Feldser D, Agani F, Iyer NV, Pak B, Ferreira G and Semenza GL (1999) Reciprocal positive regulation of hypoxia-inducible factor $1 \alpha$ and insulin-like growth factor 2. Cancer Res 59: 3915-3918

Forsythe JA, Jiang BH, Iyer NV, Agani F, Leung SW, Koos RD and Semenza GL (1996) Activation of vascular endothelial growth factor gene transcription by hypoxia-inducible factor 1. Mol Cell Biol 16: 4604-4013

Gatenby RA, Kessler HB, Rosenblum JS, Coia LR, Moldofsky PJ, Hart WH and Broder GJ (1988) Oxygen distribution in squamous cell carcinoma metastases and its relationship in outcome of radiation therapy. Int J Rad Oncol Biol Phys 14: $831-838$

Giatromanolaki A, Koukourakis M, O’Byrne K, Kaklamanis L, Dicoglou C, Trichia E, Whitehouse R, Harris AL and Gatter KC (1996) Non small cell lung cancer: C-erbB-2 correlates with low angiogenesis and poor prognosis. Anticancer Res 16: $3819-3825$

Giatromanolaki A, Koukourakis MI, Kakolyris S, Turley H, O’Byrne K, Scott PAE, Pezzella F, Georgoulias V, Harris AL and Gatter KC (1998) Vascular endothelial growth factor, wild-type p53 and angiogenesis in early operable non-small cell lung cancer. Clin Cancer Res 4: 3017-3024

Giatromanolaki A, Sivridis E, Koukourakis MI, Georgoulias V, Gatter KC and Harris AL (1999) Intratumoral angiogenesis: a new prognostic indicator for stage I endometrial adenocarcinomas? Oncol Res 11: 205-212

Giatromanolaki A, Koukourakis MI, Sivridis E, O’Byrne K, Cox G, Thorpe PE, Gatter KC and Harris AL (2000) co-expression of MUC1 glycoprotein with multiple angiogenic factors in non-small cell lung cancer suggets co-activation of angiogenic and migratory pathways. Clin Cancer Res 6: 1917-1921

Goldberg MA, Dunning SP and Bunn HF (1998) Regulation of the erythropoietin gene: evidence that oxygen sensor is a heme protein. Science 1412-1415

Gopfert T, Gess B, Eckardt KU and Kurtz A (1996) Hypoxia signalling in the control of erythropoietin gene expression in rat hepatocytes. J Cell Physiol 168: 354-361

Griffiths L, Dachs GU, Bicknell R, Harris AL and Stratford IJ (1997) The influence of oxygen-tension and $\mathrm{pH}$ on the expression of platelet-derived endothelial cell growth factor thymidine phosphorylase in human breast-tumor cells grown in vitro and in vivo. Cancer Res 57: 570-572

Gu YZ, Moran SM, Hogenesch JB, Wartman L and Bradfield CA (1998) Molecular characterization and chromosomal localization of a third $\alpha$-class hypoxia inducible factor subunit, HIF3alpha. Gene Expr 7: 205-213

Huang LE, Arany Z, Livingston DM and Bunn HF (1996) Activation of Hypoxiainducible transcription factor depends primarily upon redox-sensitive stabilization of its a subunit. J Biol Chem 271: 32253-32259
Huang LE, Gu J, Scheau M and Bunn F (1998) Reulation of hypoxia-inducible factor $1 \alpha$ is mediated by an $\mathrm{O}_{2}$-dependent degradation domain via the ubiquitine-proteasome pathway. Proc Natl Acad Sci USA 95: 7987-7992

Jiang BH, Agani F, Passaniti A and Semenza GL (1997) V-SRC induces expression of hypoxia inducible factor 1 (HIF-1) and transcription of genes encoding vascular endothelial growth factor and enolase-1: involvement of HIF-1 in tumor progression. Cancer Res 57: 5328-5335

Koukourakis MI, Giatromanolaki A, O’Byrne K, Comley M, Whitehouse R, Talbot DC, Gatter KC and Harris AL (1997a) Platelet-derived endothelial cell growth factor expression correlates with tumor angiogenesis and prognosis in nonsmall cell lung cancer. Br J Cancer 4: 477-481

Koukourakis MI, Giatromanolaki A, O’Byrne K, Whitehouse R, Talbot DC, Gatter $\mathrm{KC}$ and Harris AL (1997b) Potential role of bcl-2 as a suppressor of tumour angiogenesis in non small cell lung cancer. Int J Cancer 74: 565-570

Koukourakis M, Giatromanolaki A, Kakolyris S, O’Byrne K, Apostolikas T, Skarlatos J, Gatter KC and Harris AL (1998) Different patterns of stromal and cancer cell thymidine phosphorylase reactivity in non small cell lung cancer. Impact on neoangiogenesis and survival. British J Cancer 77: 1696-1703

Koukourakis MI, Giatromanolaki A, O'Byrne KJ, Cox J, Krammer B, Gatter KC and Harris AL (2000a) bcl-2 and c-erbB-2 proteins are involved in the regulation of VEGF and of Thymidine phosphorylase angiogenic activity in non-small cell lung cancer. Clin Exp Metast 17: 545-554

Koukourakis MI, Giatromanolaki A, Thorpe PE, Brekken RA, Sivridis E, Kakolyris S, Georgoulias V, Gatter KC and Harris AL (2000b) Prognostic and pathologic comparison of VEGF/KDR activated microvessel density (aMVD) vs. CD31 standard MVD (sMVD) in non-small cell lung cancer. Cancer Res $\mathbf{6 0}$ : 3088-3095

Maxwell PH, Dachs GU, Gleadle JM, Nicholls LG, Harris AL, Stratford IJ, Hankinson O, Pugh CW and Ratclife PJ (1997) Hypoxia-inducible factor 1 modulates gene expression in solid tumors and influences both angiogenesis and tumor growth. Proc Natl Acad Sci USA 94: 8104-8109

Maxwell PH, Wiesener MS, Chang GW, Clifford SC, Vaux EC, Cockman ME, Wykoff CC, Pugh CW, Maher ER and Ratcliffe PJ (1999) The tumour suppressor protein VHL targets hypoxia-inducible factors for oxygendependent proteolysis. Nature 399: 271-275

Mazure NM, Chen EY, Laderoute KR and Giaccia AJ (1999) Induction of vascular endothelial growth factor by hypoxia is modulated by a phosphatidylinositol 3kinase/Akt signaling pathway in Haras-transformed cells through a hypoxia inducible factor-1 transcriptional element. Blood 90: 3322-3331

Norris ML and Millhorn DE (1995) Hypoxia-induced protein binding to O2responsive sequences on the tyrosine hydroxylase gene. J Biol Chem $\mathbf{2 7 0}$ 23774-23779

O'Toole EA, Marinkovich MP, Peavey CL, Amieva MR, Furthmayr H, Mustoe TA and Woodley DT (1997) Hypoxia increases human keratinocyte motility on connective tissue. J Clin Invest 100: 2881-2891

Palmer LA, Semenza GL, Stoler MH and Johns RA (1998) Hypoxia induces type II NOS gene expression in pulmonary artery endothelial cells via HIF-1. Am J Physiol 274: 212-219

Semenza GL and Wang GL (1992) A nuclear factor induced by hypoxia via de novo protein synthesis binds to the human erythropoietin gene enhancer at a site required for transcriptional activation. Mol Cell Biol 12: 5447-5454

Semenza GL, Nejfelt MK, Chi SM and Antonarakis SE (1991) Hypoxia-inducible nuclear factors bind to an enhancer element located 3 ' to the human erythropoietin gene. Proc Natl Acad Sci USA 88: 5680-5684

Takagi H, King GL and Aiello LP (1998) Hypoxia upregulates glucose transport activity through an adenosine-mediated increase of GLUT1 expression in retinal capillary endothelial cells. Diabetes 47: 1480-1488

Talks KL, Turley H, Gatter KC, Maxwell PH, Pugh CW, Ratcliffe PJ and Harris AL (2000) The expression and distribution of the hypoxia inducible factors HIF-1á and HIF-2a in normal human tissues, cancers and tumor associated macrophages. Am J Pathol 157: 2411-2421

Tian H, McKnight L and Russel DW (1997) Endothelial PAS domain protein 1 (EPAS1), a transcription factor selectively expressed in endothelial cells. Genes Dev 11: 72-82

Tungekar MF, Gatter KC, Dunnill MS and Mason DY (1991) Ki-67 immunostaining and survival in operable lung cancer. Histopathology 19: 545-550

Volm M and Koomagi R (2001) Hypoxia-inducible factor (HIF-1) and its relationship to apoptosis and proliferation in lung cancer. Anticancer Res 20: 1527-1533

Wiesener MS, Turley H, Allen WE, Willam C, Eckardt KU, Talks KL, Wood SM, Gatter KC, Harris AL, Pugh CW, Ratcliffe PJ and Maxwell PH (1998) Induction of endothelial PAS domain protein-1 by hypoxia: characterization and comparison with hypoxia-inducible factor-1 $\alpha$. Blood 92: 2260-2268

Zagzag D, Zhong H, Scalzitti JM, Laughner E, Simons JW and Semenza GI (2000) Expression of hypoxia-inducible factor 1alpha in brain tumours: association with angiogenesis, invasion, and progression. Cancer 88: 2606-2628 
Zhong H, De Marzo AM, Laughner E, Lim M, Hilton DA, Zagzag D, Buechler P, Isaacs WB, Semenza GL and Simons JW (1999) Overexpression of Hypoxiainducible factor $1 \alpha$ in common human cancers and their metastases. Cancer Res 59: 5830-5835
Zundel W, Schindler C, Haas-Kogan D, Koong A, Kaper F, Chen E, Gottschalk AR, Ryan HE, Johnson RS, Jefferson AB, Stokoe D and Giaccia AJ (2000) Loss of PTEN facilitates HIF-1-mediated gene expression. Genes Dev 14: 391-396 